
WILLIRT \& MAKY DRRLINGTU.

MFWORINL LIBRARY

UNIVENSIIY OF PITTSBIIRBW

UNIVERSITY OF PITTSBURGH

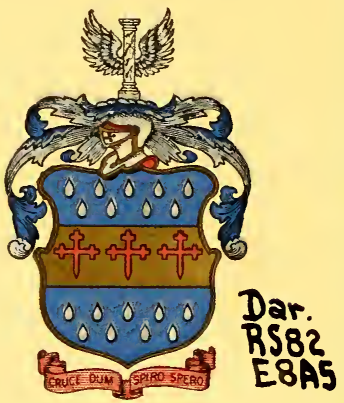

Darlington Memorial Library 







\title{
$A N$
}

\section{INAUGURAL DISSERTATION}

ON THE

\section{EUPATORIUM PERFOLIATUM:}

\author{
SUEMITTED
}

TO THE PUBLIC EXAMINATION

OE THE

TRUSTEES OF THE COLLEGE OF PHYSICIANS AND SURGEONe,

IN THE STATE OF NEW-YORK,

SAMUEL BARD, M. D. PRESIDENT,

FOR THE

Degree of Doctor of Medicine,

On the 4th day of May, 1813. 
$10^{2}$ 


\title{
JAMES ANDERSON,
}

\author{
THIS
}

\section{DISSERTATION IS INSCRIBED,}

A TESTIMONY

OF

FILIAL RESPECT AND GRATITUDE,

BY HIS SON. 
$*$
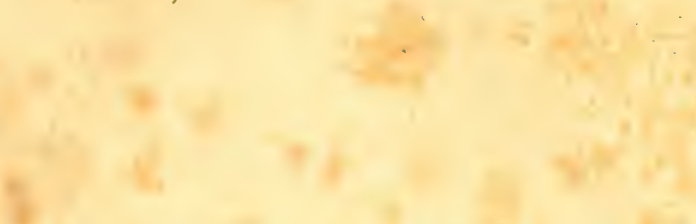

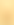

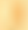

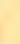

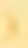

$\sqrt{2}$

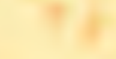

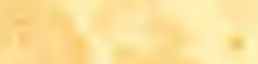
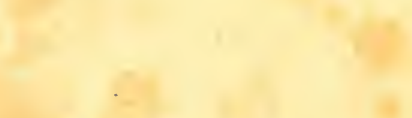

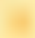<smiles>C1CCC2CCC2C1</smiles>

\section{.}

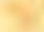

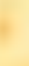

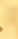

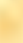

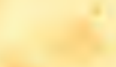

$-+n+n$

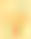

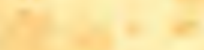

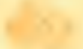

$\sqrt{2}+n^{2}$

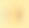

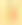

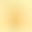

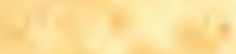




\section{DAVID HOSACK, M. D.}

\section{F. L. S. LONDON;}

Professor of the Theory and Practice of Physic and Clinical Medicine in the University of New-York; Fellow of the American Philosophical Society, and of the College of Physicians at Philadelphia; Hember of the Literary and Philosophical Society of Presion; Corresponding Member of the Medical Sociely of London, \&c. \&c.

\section{SiR,}

I DEDICATE to you this the first fruits of a medical education commenced under your care. If I were indebted to you for none other than the ordinary attentions of a preceptor toward his pupil, the obligations thence incurred would not be very great, nor the debt of gratitude perhaps difficult to be discharged. But I feel the case to be very different. Ever since I placed myself under your direction, I have witnessed in you the most anxious endeavours to facilitate my progress in my professional studies, and it would be unjust to pass over in silence the many advantages $I$ have enjoyed in your private medical school. For these, and for other favours, I feel myself greatly indebted, and take the liberty thus publicly to express to you my grateful acknowledgments.

A. ANDERSON. 


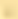

(2)

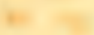

f

$+$

in

(n)

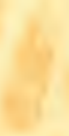

.<smiles>C1CCCCC1</smiles>

政

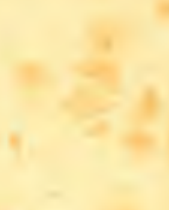

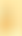
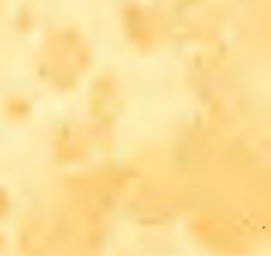

(

,
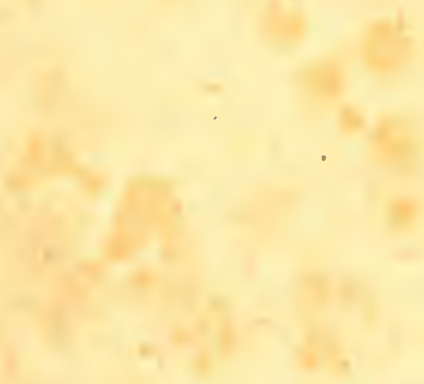

"

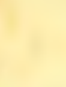

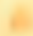

+

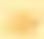
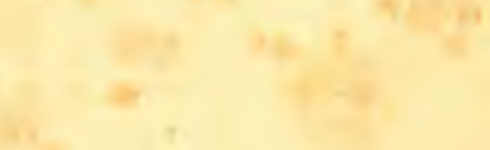

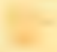

$+$ 


\section{TO \\ JOHN W. FRANCIS, M. D.}

Lecturer on the Institutes of Medicine and the Materia Medica in the College of Physicians and Surgeons in the Univer. sity of New-York, Member of the Society for the Promotion of Useful Arts in the State of New-York, \&c.

Sir,

I HAVE prefixed your name to this dedication, because, by your assistance, I have been materially aided in the course of my medical studies. It would be improper here to mention the many acts of friendship I have experienced at your hands; but be assured they have caused the deepest impression on my mind, and that the recollection of them will not readily. 'ie obliterated.

THE AUTHOR. 



\section{PREFACE.}

THE object of the following Dissertation is to ascertain the medical virtues of one of the indigenous productions of this country, and thus to increase the materia medica of the United States. For this purpose the writer made choice of the Eupatoridu PerfoliATUM, one of the most common of our vegetable products, and which for a considerable time has been employed as a domestic remedy in the manugement of certain diseases. The subject seemed to divide itself more particularly into three general heads, and accordingly it has been considered, first, as to its botanical description; secondly, as to its character as ascertained by chemical analysis; and, thirdly, as an article of medicine. Under the first head, little more has been said than to offer to the reader a concise botanical account of the plant. As to the second head, with a view of distinctly ascertaining its chemical properties, a series of experiments was instituted. These have been detailed with as much brevity as nas thought consistent with perspicuity; and, with the observations made upon the experiments, the component parts of this vegetable, as far as ascertained by analysis, are given. On this part of his subject, it would be injustice in the 
writer not to state the obligation he is under to $\mathrm{Mr}$. George Chilton, of this city, for the many pure and delicate tests with which he furnished him, and by which he was materially aided. In the third division of the subject, the application of the Eupatoriam Perfoliatum as an article of the materia medica is considered. Its utility in this respect, it is hoped, has not been exaggerated, as nothing has been asserted that experiment did not seem to warrant; and beside, the opportunities which the writer enjoyed of witnessing its effects in the treatment of various diseases, during his attendance at the Alms-house of this city, fully confirm, in his opinion, all that has been said of its medical virtues.

New-York, May 3, 1813. 


\title{
A \\ DISSERTATION
}

\author{
ON THE
}

\section{EUPATORIUM PERFOLIATUM}

$$
\text { OF }
$$

\section{LIN N EUS.}

The genus Eupatorium, according to the artificial system of LinNeus, is arranged under the class syngenesia, order polygamia æqualis, and is described in the following manner:

Cal. Communis oblongus, subcylindricus: imbricatus : squamis lineari-lanceolatis, erectis, inæqualibus.

Cor. Composita uniformis, tubulosa: Corollula hermaphroditæ, æquales. 
Propria monopetala, infundibuliformis : limbo quinquefido, patulo.

Stam. Filamenta quinque, capillaria, brevissima. Anthera cylindracea, tubulosa. Pist. Germen minimum. Slylus filiformis, longissimus, ad stamina usque bifidus, rectus. Stigmata tenuia.

Per. nullum. Calyx immutatus.

Sem. solitaria, oblonga. Pappus capillaris s. plumosus, longus.

REc. nudum.*

In his natural orders, Linnæus has placed the eupatorium among the composita discoi$d a$. In the Ordines Naturales of Mons. JussIEU, the eupatorium is arranged in his tenth class, the character of which is dicotyledones monopetalæ, corollæ epigynæ, antheræ connatæ. Order the third corymbiferæ.

This genus of plants appears to have been known at a very early date. In the writings

* Genera Plantarum, No. 1272. 
of Avicenva, mention is made of the eupatorium; but from the imperfect account which he has given, and from the obscurity which pervades the descriptions of the older botanical writers, it is impossible to determine its precise character. By some, however, the eupatorium of Avicenna is supposed to be the eupatorium cannabinum of CAsper BauHin. The celebrated WILLdenow, in his enumeration of the species of this genus of plants, has placed under the name of eupatorium cannabinum, this species of CAsper BauHin, which Fuschius has noticed as the eupatorium adulterinum. In the Historia Plantarum Universalis of John BAuHrn we are furnished with a description, at some length, of the eupatorium adulterinum. This species has been considered, by some, as belonging to the genus eupatorium; but this arrangement has been rejected by Professor Willonewow.

Miller enumerates forty-nine species of this genus of plants; and in the late work of WiLLDENow seventy-one species are given, of 
which sixteen are indigenous to the United States. Persoon, whose enumeration is still more complete, has, in his Synopsis Specierum Plantarum, seventy-five species ; of these, seventeen are considered as the products of this country. The species to which the writer more particularly intends to confine his attention, on the present occasion, is the EUPATORIUM PERFOLIATUM of LinNeUs.

This species is thus designated :

E. Perfoliatum, foliis connato perfoliatis tomentosis. Lin:

E. Virginianum. Morris Hist.

E. Virginianum. Pluk. Alm.

E. Connatum. Mich. Flor. Bor. Amer.

This plant is familiarly known throughout the United States, and is distinguished by a great variety of nåmes; such as thoroughwort, Indian-sage, cross-wort, bone-set, vegetable antimony, \&c. It is indigenous to this country, and may be found from Canada to the Floridas: it naturally delights in stand- 
ing waters and in low marshy situations, and is sometimes seen to flourish near salt water. In the state of New-York it is found very abundantly, and grows from three to six feet in height.

Root, horizontal, fibrous, perennial.

Stem, upright, hairy.

Leaves, opposite, united at their base, serrated, growing narrower at their points, rough, downy underneath, slightly decurrent.

Foot stalk of the flowers, opposite, axillary, long, hairy.

Flowers, compound, terminal, white. Seeds, oblong, feathery.

This plant makes its appearance in the neighbourhood of this city in May, it flowers in July, and produces seed in September.

The eupatorium perfoliatum has for some time been well known to possess very active medicinal virtues; though its use has been 
limited principally to the domestic prescriptions of families remote from our principal cities. It has long been employed by many of our Indian tribes, as a successful remedy, in the treatment of intermitting and remitting fevers; and such is supposed to have been its efficacy in the cure of these diseases, that it acquired the name of ague-weed. It has also been employed in other diseases, in which emetics and sudorifics were indicated; and in certain preparations, recourse has been occasionally had to it as a tonic. In the treatment of the yellow fever, as it has prevailed in different parts of the United States, and in other febrile disorders, its efficacy, as an active sudorific, has been acknowledged by many respectable writers. With a view, however, of ascertaining more particularly the peculiar properties of this plant, and its virtues as an article of the materia medica, the following experiments were instituted. Its application in the treatment of diseases, as deduced from these experiments, with the opportunities which the writer has enjoyed 
of witnessing its effects, will be considered in a subsequent part of this dissertation.

\section{EXPERIMENTS.}

Decoctions were made of the flowers, leaves, and roots: to an ounce of each of these parts of the plant, bruised and put in separate glass vessels, was added one pint of distilled water. After having been subjected to the heat of a sand-bath, and boiled for one hour, it was filtered through paper. The decoction of the leaves had the least colour; that of the flowers was somewhat darker; that of the roots presented the darkest colour. They all exhibited shades of brown. To the taste they were bitter; but this sensation was most produced from the leaves, and least from the root. 


\section{EXPERIMENT I.}

A decoction of the flowers, prepared in the above manner, with an infusion of litmus formed a red colour; a solution of sulphate of iron changed it to a dark green; an infusion of galls formed a very slight precipitate; with $\mathrm{mu}$ riate of tin recently prepared, it caused a precipitate of a brownish yellow colour; the nitrate of mercury formed a precipitate; with muriate of barytes a precipitate was formed; oxalate of ammonia produced a turbidness, which was followed by a white precipitate; sulphuric acid formed a precipitate ; a solution of tartarised antimony had no effect; with pure ammonia it acquired a green colour ; pure potash caused a brownish precipitate; gelatin produced a trifling precipitate; a solution of nitrate of silver formed a precipitate ; chromic acid produced a copious olive green precipitate; the acetate of lead caused a light green; the nitrate of lead induced a slight precipitate; with the carbonate of potash a precipitate also was formed. 


\section{EXPERIMENT II.}

The following re-agents were then tried with the decoction of the leaves: An infusion of litmus formed a red colour; with an infusion of galls no precipitate was formed; muriate of tin caused a brownish yellow precipitate, but not so copious as in the first experiment; oxalate of ammonia produced a copious white precipitate; pure potash formed a greenish precipitate; with gelatin a copious precipitate was induced; pure nitrate of silver caused a copious whitish precipitate; the acetate of lead formed a yellowish precipitate; nitrate of lead produced an abundant precipitate. As in the decoction prepared from the flowers, a solution of the sulphate of iron, nitrate of mercury, muriate of barytes, sulphuric acid, tartarised antimony, pure ammonia, chromic acid, carbonate of potash, produced effects similar to those mentioned in experiment the first. 


\section{EXPERIMENT III.}

The decoction of the root subjected to experiment produced the following results: An infusion of litmus induced a red colour ; a solution of the sulphate of iron changed it to a green, but not so dark as in the two last experiments ; an infusion of galls, like that prepared from the leaves, caused no precipitate; with muriate of tin, a copious precipitate was formed ; nitrate of mercury formed a copious white precipitate; oxalate of ammonia formed a turbidness; pure potash produced a brownish green colour, and in both these respects was similar to those obtained from the flowers. With gelatin no precipitate was evident; nitrate of silver caused a copious whitish precipitate, similar to that produced from the decoction of the leaves; acetate of lead formed a slight greenish precipitate; nitrate of lead induced quite a copious precipitate: with the muriate of barytes, sulphuric acid, tartarised antimony, pure ammonia, chromic acid, carbo- 
nate of potash, appearances and precipitates were produced nearly in every respect the same as those related in experiments the first and second.

\section{EXPERIMENT IV.}

A decoction of the flowers prepared as in the former experiments, was evaporated to the consistence of syrup. A portion of very pure alcohol was poured upon it, and after infusing twenty-four hours, was poured off. Fresh alcohol was then added, and this was suffered to stand for twenty-four hours, and again decanted. This process was repeated, until the alcohol exhibited no change of colour whatever. After all the alcohol had been decanted and mixed, it appeared of a brown colour, and had a bitter taste. It produced the following results: with an infusion of litmus, it formed a red colour; with acetate of lead a light green; no precipitate was caused by tartarised antimony ; barytic water formed a light yellow ; with sulphate of iron 
it produced a green precipitate; with distilled water no precipitate.

\section{EXPERIMENT V.}

A decoction of the leaves, treated in the same manner as in experiment the fourth, exhibited the following appearances: An infusion of litmus formed a red colour; a solution of the acetate of lead formed a copious light green; with distilled water a precipitate was formed ; carbonate of potash caused a copious brown precipitate; nitrate of lead produced a copious light green precipitate; nitrate of mercury induced a copious white precipitate; barytic water formed a dense copious precipitate. The effects produced by tartarised antimony, and with the sulphate of iron, were in no respects different from those mentioned in the last experiment.

EXPERIMENT VI.

A decoction of the root was also prepared in the same manner, and the action of the same 
re-agents was in nowise different from those noticed in experiment the fourth. With the carbonate of potash, however, which was now employed, an ochre yellow was produced.

\section{EXPERIMENT VII.}

The brownish matter, not taken up by the alcohol in the last three experiments, was dissolved in distilled water in separate vessels; a portion of a dark brown substance was left from each. These watery solutions, after having been evaporated to dryness, left a hard brittle extract, of a brown colour, which, upon being re-dissolved, possessed a sweetish taste.

\section{EXPERIMENT VIII.}

A portion of the alcoholic solutions mentioned in the fourth, fifth, and sixth experiments, was evaporated nearly to dryness ; a resinous matter was left of a yellowish brown colour, an extreınely bitter taste, and completely soluble in warm water. These watery 
solutions were examined, and exhibited the following habitudes, with re-agents. The solution obtained from the flowers with carbonate of potash caused a brown colour; it formed a precipitate with barytic water; with an infusion of litmus, a faint red appearance ; both the acetate and nitrate of lead formed a precipitate; a solution of the sulphate of iron caused a green precipitate; tartarised antimony had no effect, nor the nitrate of silver; gelatin produced no change; alcohol formed a precipitate; muriate of tin formed a reddish brown precipitate.

\section{EXPERIMENT IX.}

The solution of the resinous matter obtained from the leaves exhibited the following appearances: With the carbonate of potash it formed a brown precipitate; with barytic water an abundant precipitate was induced; with litmus no change was discernible; the acetate of lead caused an abundant yellowish white precipitate; with nitrate of lead a precipitate 
of a whitish yellow colour, and in large quantity, was induced; with a solution of sulphate of iron an abundant dark green precipitate was formed; tartarised antimony formed a greenish brown precipitate; nitrate of silver formed a copious whitish yellow precipitate; a reddish brown precipitate was readily produced by the muriate of tin.

\section{EXPERIMENT X.}

The solution of the resinous matter obtained from the root was likewise subjected to the operation of the same re-agents. With carbonate of potash no effect was visible; barytic water formed a slight precipitate: an infusion of litmus, as in the leaves, caused no change: with the acetate of lead a slight precipitate was formed; nitrate of lead produced scarcely any turbidness; the sulphate of iron induced a green precipitate; tartarised antimony had no effect; the nitrate of silver formed a trifling precipitate; no precipitate was visible from gelatin, though readily produced by the action 
of alcohol ; the muriate of tin formed a trifling precipitate.

In the following experiments, by means of the cold infusions, which were next instituted, one ounce of the flowers, the same quantity of the leaves, and of the roots, bruised, was put in separate glass vessels, and a pint of distilled water added to each. They were suffered to infuse for twenty-four hours, and then filtered through paper. The infusion of the root possessed the darkest colour, that of the leaves was considerably lighter, while that of the flowers was still lighter. In all a bitterish. taste was perceptible.

\section{EXPERIMENT XI.}

An infusion of the flowers, prepared in the manner just mentioned, produced the following appearances. With re-agents an infusion of litmus formed a red colour; a solution of the sulphate of iron formed a green precipitate; an infusion of galls induced no precipi- 
tate; muriate of tin recently prepared caused a precipitate ; nitrate of mercury formed a copious white precipitate; with muriate of barytes a slight turbidness was formed; oxalate of ammonia likewise caused a precipitate; by sulphuric acid a slight turbidness was discernible; neither tartarised antimony, nor pure ammonia produced any sensible effect; with pure potash a greenish brown colour was effected; gelatin formed no immediate precipitate; a solution of nitrate of silver formed a whitish precipitate; chromic acid caused a copious precipitate of a greenish brown colour; the nitrate of lead formed a very copious precipitate; a solution of the carbonate of potash produced a brown colour.

\section{EXPERIMENT XII.}

An infusion of the leaves produced the following appearances with re-agents. A red colour was induced, by an infusion of litmus; a solution of the sulphate of iron formed a 
very dark green precipitate; oxalate of ammonia caused an immediate and copious precipitate; sulphuric acid formed a slight turbidness; pure ammonia formed a greenish colour; gelatin formed a precipitate; nitrate of silver formed a very copious precipitate; carhonate of potash formed a brown precipitate; with the infusion of galls, muriate of tin, nitrate of mercury, muriate of barytes, tartarised antimony, pure potash, chromic acid, and the nitrate of lead, effects similar to those enumerated in experiment the eleventh were produced.

\section{EXPERIMENT XIII.}

With an infusion of the root, prepared after the manner of the two preceding experiments, the following effects were produced. With àn infusion of litmus, a red colour was formed; nitrate of mercury formed a greyish precipitate; muriate of barytes formed a precipitate; oxalate of ammonia formed no precipitate; pure ammonia caused 
no change; gelatin had no effect; nitrate of silver caused the same change as in experiment the eleventh; nitrate of lead formed a precipitate, though not so copious as with the infusion of the flowers or leaves: neither the carbonate of potash, nor muriate of ammonia produced any sensible alteration. The effects caused by the sulphate of iron, infusion of galls, muriate of tin, sulphuric acid, tartarised antimony, pure potash, and chromic acid, were in no respects different from those already stated in experiment the eleventh.

\section{EXPERIMENT XIV.}

Infusions of the flowers, leaves, and of the root, prepared as in the last three experiments, were put in separate retorts and distilled. After nearly one half had come over, the receivers were changed, and the other part in like manner distilled off. The first three portions of the distillation were then examined by a number of re-agents, without the least sensible change being apparent. 
The last three distillations were then examined. That obtained from the infusion of the flowers formed a red colour with the infusion of litmus: with the sulphate of iron no effect was visible, nor with the acetate of lead. I also tried a number of other tests, without producing any particular alteration.

\section{EXPERIMENT XV.}

The product of the distillation from the infusion of the leaves exhibited the same appearances as in the last experiment.

\section{EXPERIMENT XVI.}

The product of the distillation from the infusion of the root occasioned the same appearances as in the two last experiments.

\section{EXPERIMENT XVII.}

After the distillation of the infusion of the flowers, of that from the leaves, and also of 
that from the root, which was continued to dryness, an extract was left in the retorts of a dark colour and of a very bitter taste. Upon the addition of solid caustic soda, fumes resembling burning sugar were disengaged, and in a few minutes after the smell of ammonia was very evident.

\section{EXPERIMENT XVIII.}

The flowers, leaves, and roots that were used in the cold watery infusions, after having been repeatedly washed, were put in separate retorts, and a quantity of distilled water added to each. They were placed in a sand bath, and distilled; after nearly one half had come over, the receivers were removed, and fresh receivers luited to the retorts. The first part of the distillations appeared clear, had no taste, and but very little smell. The following re-agents had no effect upon them; viz. the infusion of litmus, a solution of the sulphate of iron, carbonate of potash, nitrate of silver, and acetate of lead. 


\section{EXPERIMENT XIX.}

After all the fluid that was left in the retorts in the last experiment had come over, and the materials were left completely dry, the distilled fluid exhibited a milky appearance, with some films floating in it; there was scarcely any appearance of oil on the surfaces. It had a vegetable smell: upon being subjected to experiment, with an infusion of litmus, it acquired a red colour. Neither a solution of the sulphate of iron, tartarised antimony, carbonate of potash, acetate of lead, muriate of mercury, chromic acid, or nitrate of lead, produced any alteration.

\section{EXPERIMENT XX.}

Finding there was nothing but an acid obtained from the distillation of the materials, and suspecting it to be the acetic, I took the product of the distillation made with the leaves, and saturated it with pure potash. Af- 
ter it was evaporated, a crystalline mass was obtained, upon which sulphuric acid was poured. Fumes like aromatic vinegar arose.

\section{EXP RRIMENT XXI.}

'To the flowers, leaves, and roots that were employed in experiment the eighteenth, a quantity of very pure alcohol was added: they were suffered to infuse for twenty-four hours, and the infusion then decanted. The appearance of the alcoholic infusion of the flowers was of the colour of Madeira wine, and possessed a bitter taste and an aromatic flavour. With the infusion of litmus, it formed a red colour; a solution of sulphate of iron produced a dark green; barytic water formed a brownish yellow; nitrate of lead created a slight precipitate; with the acetate of lead it caused a brown precipitate; carbonate of potash formed a slight brown precipitate; tartarised antimony and gelatin had no effect upon it; distilled water formed a precipitate. 


\section{EXPERIMENT XXII.}

The alcoholic infusion of the leaves was of a brown colour, and like that obtained from the flowers, was of a bitter taste and aromatic flavour. With re-agents this infusion exhibited the following appearances: carbonate of potash formed a dark brown precipitate; tartarised antimony produced a brownish precipitate; nitrate of silver caused a light colour; with the acetate of lead an ochre yellow precipitate was formed; nitrate of mercury occasioned an olive green precipitate; barytic water also formed an olive green; muriate of mercury caused a slight precipitate; a light green colour was induced by nitrate of copper; pure potash created a brown colour; oxalate of ammonia produced a white precipitate; with gelatin a precipitate was formed; a solution of sulphate of iron, litmus, and distilled water, produced effects similar to the same re-agents, in experiment the twenty-first. 


\section{EXPERIMENT XXIII.}

The alcoholic infusion of the root also acquired a dark colour, but did not possess the bitter taste nor aromatic flavour. It produced the following effects: with carbonate of potash a copious dark precipitate was formed; the acetate of lead caused a slight brown precipitate; the infusion of litmus, sulphate of iron, nitrate of lead, barytic water, and tartarised antimony effected changes similar to those detailed in experiment the twentyfirst.

\section{EXPERIMEN'T XXIV.}

A portion of the alcoholic infusion of experiment the twenty-second was distilled. It was of a very clear appearance; had no aromatic smell nor bitter taste; an infusion of litmus, a solution of the sulphate of iron, and a number of other re-agents were tried, without producing any change. 
EXPERIMENT XXV.

A part of the alcoholic infusion of the leaves had recourse to in experiment the twenty-second, was evaporated to dryness. A yellow resin-like thick varnish covered the bottom of the capsule, and was of an extremely bitter taste. Repeated affusions of warm water separated a part of it, leaving the remainder of a deep transparent red colour. These watery portions, when added together, were of a yellow colour; on standing they soon became opaque, and deposited the resin which, by means of the heat, they had taken up.

\section{EXPERIMENT XXVI.}

To the leaves that were used in experiment the twenty-first, a quantity of very pure alcohol was added, and the mass distilled to dryness : upon the infusion of litmus being poured upon the product of the distillation, a red colour was formed; a solution of the sulphate 
of iron, gelatin, and a number of other reagents were tried, but without causing any evident alteration.

\section{OBSERVATIONS}

ON

THE EXPERIMEN'TS.

From the introductory remarks, preceding the experiments, it will be perceived, that a great part of the virtues of the eupatorium perfoliatum are readily obtained by means of a simple decoction. Were we to judge from the colour produced from a decoction of each part, we might conclude that the root possessed the most active properties; but from the bitter taste, and from other circumstances, hereafter to be mentioned, as deduced from the experiments, it is abundantly evident, that 
they reside in greatest quantity in the leaves, and least in the roots.

Experiment the first, with the flowers, proves the presence of a free acid, as is evinced from the infusion of litmus forming a red colour. The action of the sulphate of iron may arise from some modification of the gallic acid. Though it is stated, that the infusion of galls formed a very slight precipitate, yet as this effect was not produced until several hours had elapsed, and as I was unahle to effect the same experiment a second time, either with the flowers or any other part, by means of the same re-agents, no satisfactory conclusion can be deduced as to the presence of cinchonin. The extractive matter was readily evinced, from the lrownish precipitation caused by the muriate of tin, and from the precipitate induced by the nitrate of mercury : the extractive principle was also shown by the muriate of barytes. The turbidness produced with the oxalate of ammonia was conjectured to contain lime; and as, in a 
subsequent experiment, we found it in an alcoholic solution, it is probably united with acetic acid. The sulphuric acid proved the presence of extract. 'The effect of the alkalies proves the presence of extract. The tannin principle was proved by the gelatin. The precipitate formed by the nitrate of silver was owing to extract. The changes produced by chromic acid, and the olive green precipitate formed, may probably be accounted for by the deoxidation of the acid itself, from the action of extract. 'The acetate and nitrate of lead also afforded tannin and extract. Taunin was also made evident by the action of the carbonate of potash.

From experiments second and third, it was ascertained, that the extractive matter is in less quantity in the leaves than in the flowers, and that it may be obtained abundantly from the roots. More of lime was proved to exist in the leaves, than in either the flowers or roots. Judging from the precipitate formed by pure alkali, there would seem to be little 
difference in the proportion of tannin and of extractive matter in the flowers and roots. Most tannin is also shown to reside in the leaves. From the nitrate of silver we have proof that the extractive* principle resides especially in the root. That the leaves possess the greatest quantity of tannin is likewise shown from the action of gelatin.

The extract obtained after the manner detailed in experiment the fourth, evidently possessed properties similar to those found in the decoction. The free acid was manifested by the infusion of litmus, and modified gallic acid by the sulphate of iron. No change being caused by distilled water, the total absence of any resinous material may be inferred. That the leaves possessed more or less resinous matter, was proved by the fifth experiment. The presence of tannin

* Though I have here and elsewhere denominated this principle, obtained from the root, the extractive, yet it appears to unite the characters both of extract and gum. 
and extract is also proved. From the sixth experiment we obtain the same results as in the preceding. The ochre colour which the solution acquired by the carbonate of potash was owing to extractive. Little need be said of experiment the seventh; it showed the presence of gum united to extract and tannin.

From experiment the eighth a principle was obtained which was soluble in alcohol and in water. Vauquelin, in his examination of the Peruvian bark, also discovered a similar material, which he is inclined to believe a new principle; he calls it a resiniform matter.*

* From the re-agents employed in this experiment, a conclusion might perhaps be drawn, that this principle approached to the nature of that denominated by Dr. THomson, in his system of chemistry, artificial tamnin, or the second species of bitter principle. Mr. CHENEv Ix procured this principle from a filtered preparation of digested unburned coffee, in water; and, though I had not an opportunity of making use of all the re-agents that he employed in his examination, yet it seems to be highly probable that the eupatorium contains a material very analagous to that found in coffee. From the experiments of LAGRANGE, it appears, that a substance 
All the re-agents had recourse to in experiments the ninth and tenth established the evidence of the resiniform matter of $\mathbf{V}$ AUQUELIN, and that it is to be obtained most abundantly from the leaves, and least from the roots.

From the effects of tartarised antimony, in experiment the ninth, it would appear to contain a principle which Dr. Duncan calls cinchonin.*

similar to this second species of bitter principle exists in the flowers of the arnica montana. Dr. Tномson thinks, that bitter principle, which characterizes the worm-wood, sabine, rue, milfoil, and chamomile, belongs to this second species. It will hereafter appear, that the virtues of the eupatorium perfoliatum, as an article of medicine, are very similar to those for which these plants are distinguished; more particularly those of the anthemis nobilis. See Thomson's Chemistry, vol. v. p. 95: see also experiments on the various species of cinchona, by M. VAvquelin, in $\mathrm{NI}_{\text {- }}$ cholson's Journal, 8vo. vol. 19, p. 204.

* See Dr. Duncan's experiments on the Peruv. bark, in NichoLson's Journal, 8vo. vol 6, p. 225. 
It is scarcely necessary to remark, that the virtues of the eupatorium are extracted in a considerable degree by means of the cold watery infusion. From what has been stated, it will be recollected, that the infusion of the root of this plant, like the decoction made of the same part, afforded the darkest colour; and that while the decoction of the flowers was darker than that made with the leaves, that the infusion of the leaves was considerably deeper than that prepared from the flowers.

Experiment the eleventh was instituted for the purpose of ascertaining how far its active properties were imparted to the cold infusion. The same re-agents as were employed with the decoction were tried with the infusion of the flowers. The results were nearly similar; the presence of an acid, of tannin, and of extractive matter was proved, though the astringent principle was not so abundant. Experiments twelfth and thirteenth fully evince that in the leaves reside the most active properties of the plant; the dark green precipitation caused by 
sulphate of iron, and the precipitation induced by gelatin, manifested the existence of tannin and modified gallic acid in the leaves, while, with the same re-agents, the root was ascertained to be nearly destitute of it. The oxalate of ammonia, by the immediate and copious precipitate which it caused, while it convinced us that the leaves also possessed lime, in no small degree, it rendered it no less certain, in our experiments with the root, that from this portion of the plant, this ingredient was not to be obtained, at least in any sensible quantity. By the other tests it is also proved, that the virtues of the root, while they differ in quality, are also less in quantity.

I have stated the results of the simple decoction, and of the simple infusion. With the view of ascertaining more satisfactorily the properties of the plant, as taken up by this last preparation, I subjected the infusion itself to the process of distillation. After the process had been continued until nearly one half had come over, upon examination, nothing but 
pure water was ascertained to be in the receiver. The remaining portion being distilled over into other receivers, I employed the usual re-agents. 'This last product, obtained from the distilled infusion of the flowers, showed a free acid; that it was not the gallic acid was certain from the inaction of the sulphate of iron: of its being the acetic acid, there could be little doubt, both on account. of the difficulty with which it was volatilized, and from the result of experiment twentieth. On experiments fifteenth and sixteenth it is unnecessary to make any particular remarks.

From experiment the seventeenth, a dry extractive matter, similar to that obtained from the decoction, was produced. From the operation of the caustic soda we infer the existence of azote. Experiments eighteenth and nineteenth tend to corroborate the results of the fourteenth, fifteenth, sixteenth, and twentieth experiments. From the nineteenth experiment acetic acid was produced, which was probably modified by the presence of oil. 
The twenty-first, twenty-second, and twentythird experiments prove, that pure alcohol extracts all the active principles which exist in the decoction and infusion; and in addition, also a resinous matter. It will be perceived, that alcohol takes up tannin from the leaves, and that this constituent of the plant is not extracted from the other parts by this menstruum. Experiment the twenty-fourth proves that the acid is not volatilized in the temperature of boiling alcohol. From experiment the twenty-fifth, we have the resin more pure than heretofore, and, comparatively speaking, in liberal quantity. A portion of the resinous matter was dissolved in warm water, and was easily precipitated upon cooling. From the last experiment we learn, that in the distillation of the plant with pure alcohol, the free acid only is extracted.

From the experiments which were instituted, and the results which $I$ have attempted to deduce from them, it seems to be satisfactorily proved, that the eupatorium perfoliatum 
contains, firstly, a free acid; secondly, tannin; thirdly, extractive matter; fourthly, a gummy matter ; fifthly, a resin; sixthly, azote; seventhly, lime, probably the acetate of lime; eighthly, gallic acid, probably modified ; ninthly, a resiniform matter, soluble in water and in alcohol, and which seems to contain a bitter principle. That the free acid may be obtained from all parts of the plant: that tannin is obtained in much the largest quantity from the leaves, and least from the roots: that the extractive and gummy matter resides chiefly in the roots: that the leaves and flowers also contain a larger proportion of resin than the roots: that azote exists in the flowers, leaves, and roots.

I have stated the presence of gallic acid; whether it depend upon the combination of a free acid with tannin, or whether it is to be ascribed to the existence of extractive matter, an opinion which Dr. Thомson maintains, I do not pretend to determine: that lime, a constituent of Peruvian bark, was also 
liberally procured from every portion, though it abounded in the leaves, is also apparent. Hence we are warranted in the conclusion, that this plant possesses active medicinal properties; that many of them are similar to those which characterize the cinchona officinalis, the anthemis nobilis, and other valuable articles of the materia medica; but that these virtues reside in greatest quantity in the leaves.*

As pharmaceutical preparations of this species of the eupatorium, the following seem to be more particularly deserving of recommendation. The decoction of the flowers and of the leaves; infusions of the same parts; the leaves in substance, pulverized ; and a tincture of the flowers and of the leaves, prepared with proof spirits. This last form is the most pleasant and convenient, and at the same

* A contrary opinion is expressed by Dr. Barton, who maintains, that the flowers possess the most active properties; but it is unnecessary to enter into a refutation of this point after the analysis which has been given. 
time the most powerful; for proof spirits was ascertained to be the best menstruum.

On the use of the Eupatorium Perfoliatum as an article of the Materia Medica.

Of the value of the eupatorium perfoliatum, as an article of medicine, there can be no hesitation to offer an opinion. Though the writer has forborne to institute a comparison between the chemical properties of this plant, as deduced from experiment, and of those which are ascertained to belong to the Peruvian bark, yet the inference can be readily drawn, that, in very many respects, these two products of the vegetable kingdom are exactly similar. Indeed, it may readily be asserted, that, for its active medicinal virtues, particularly as a sudorific and as a tonic, it will not suffer by comparison with any of the articles drawn 
from the vegetable kingdom. Of its modus operandi in the treatment of diseases, it will be unnecessary particularly to dwell; this will be sufficiently well understood in connection with the circumstances that will be given when its employment in various disorders is considered. Many of the remedies procured from the class of vegetables which, from repeated experience, have been found particularly useful in the treatment of diseases, doubtless produce their salutary effects, by operating in the same manner as this species of the eupatorium. Such may be considered the marubium vulgare, the anthemis nobilis, \&c.

From the opportunities which I have enjoyed of witnessing the employment of this plant, in different diseases, in the New-York Almshouse and from the observations and experience of several distinguished practitioners, particularly of Dr. Barton and of Dr. Hosack, I am led to believe it an important and efficacious remedy in the treatment of most febrile disorders, particularly in intermitting 
and remitting fevers, yellow fever, and in other disorders of specific contagion ; in many cutaneous affections, and in diseases of general debility.

Let us first consider its use in intermitting and remitting fevers. The great efficacy of eupatorium perfoliatum in this class of diseases has been long known, as the facts communicated by Dr. Barton fully prove.* The following cases are inserted for the purpose of showing that these diseases may as effectually be cured by this indigenous product of our own country as by the bark of Peru. Perhaps it may be necessary to mention, that its operation depends, in a very great degree, upon the particular form in which it is administered. If it be exhibited as a warm decoction, it often proves emetic, and acts especially upon the skin, in producing diaphoresis: if it be given in the form of a cold infusion or decoc-

* Collections towards a Materia Medica of the United States. 
tion, or in substance, it acts as a powerful tonic. In order to evince its tonic effects, it was given in these cases of

\section{Intermittent Fever.}

CaSE I. Francis $\mathrm{C}-\mathrm{y}$, born in Ireland, aged forty-nine, was admitted in the NewYork Alms house, Oct. 1, 1812: is naturally of a fair complexion; at present is very much debilitated, and affected with a quartan intermittent, which generally attacks him at four o'clock in the morning, and continues until eleven o'clock, A. M. ; complains of considerable pain in his extremities; pulse rather frequent; bowels regular; tongue furred; appetite very bad.

These attacks began eight weeks since, but have always put on the appearance of a regular quartan, and have varied but little in the time of attack. He was employed on a farm in Westchester, in a marshy situation; has not as yet taken any medicine for his complaint. 
Ordered, Pulv. ipecac. grs. xv.

Tart. antim. grs. ii. M.

Oct. 2. The emetic operated very well, and brought a quantity of bilious matter from his stomach, by which he feels somewhat better. Put him upon the use of the

Pulv. fol. eupat. perfol. grs. xx.

one to be taken every two hours in syrup, during the intermission of the fever. Oct. 4. This day the fever ought to have come on at or about four o'clock: experienced some sensations of chilliness, and a slight degree of fever, but these left him in a short time; says the medicine sets well on his stomach: pulse natural; bowels regular; tongue a little furred; skin moist: let him continue in the use of the pow ders. Oct. 7. This morning escaped the paroxysm; says he feels much better; observes his urine is increased in quantity: let him continue in the use of the eupatorium.

Oct. 10. This morning felt some coldness 
about the time of attack, but no chill or fever; does not complain of the taste of the powders: let him continue in the use of the medicine. Oct. 11. Does not feel so well this morning, and is at times inclined to vomit: let him increase the dose of his medicine, and take pulv. fol. eupat. perfol. grs. xxv. every two hours. Oct. 13. Had no attack of fever this morning, but as he complains of his bowels being costive, a gentle cathartic was given him. Oct. 16. The purge given operated but once; has not taken any of the powders since the last report; had another attack of fever this morning. The chill came on about eight o'clock, but was very soon checked, by giving a strong decoction of the flowers of the eupatorium: it operated as an emetic, and was followed by a copious secretion from the skin: ordered him to continue in the use of the powders, increasing the dose to 3 fs. every two hours, while free from fever.

Oct. 19. Has not had any fever since the last report ; pulse full; bowels regular ; skin moist ; 
tongue clean; appetite better: has taken half an ounce of the medicine since the last report: let him continue in the use of the powders.

Oct. 22. $C-y$ still continues free from fevers; takes at least 3 fs. of his powders every two hours: is gaining strength rapidly: let him continue in the use of the eupatorium. Oct. 29. Our patient has not had any fever since the sixteenth instant; has regained his appetite and strength, and wishes to be discharged; accordingly took his discharge from the house this morning.

Nov. 18. Accidentally saw our patient; informs me he has not had any return of his disease since.

CASE II. Catharine H-y, born in NewYork, aged thirty-six, is affected with a tertian intermittent, which generally attacks her at eleven o'clock in the evening, and continues with great violence until three or four o'clock in the morning. Pulse natural; bowels rather slow ; tongue furred; appetite much impaired. 
The first attack she had, was on the night of the twenty-ninth of Sept. at eleven o'clock. Let a strong decoction of the flowers of the eupatorium be given.

Sept. 30. The decoction operated as an emetic, and brought a considerable quantity of half formed bilious matter from her stomach : ordered, pulv. fol. eupat. perfol. grs. xx. in syrup, every two hours, while free from fever. Oct. 2. Our patient had another attack of fever last evening; let her continue in the use of the medicine. Oct. 4. She has escaped from her fever last night, does not complain of the taste of the powders, and has taken them regularly since the last report: pulse natural; howels regular; skin moist; urine increased in quantity; appetite better : let her continue in the use of the powders. Oct. 6. Still continues free from fever, since the first instant.

Oct. 15. $H-y$ still continues free from fever. It is two weeks since she had an attack of the disease. Discharged, cured. 


\section{CAse III. Hannah $D-n$, born in Ireland,} aged thirty-six, is affected with a quotidian intermittent. The chill comes on at two o'clock in the afternoon, and continues until eight o'clock in the evening: was attacked on the fourth of October. Pulse full and slow; bowels costive; skin cool ; tongue clean; some pain in the head: says she lived at Poughkeepsie about three months since, and while there had a disease called spotted fever, of which she was relieved, but was left in a very debilitated state: she removed to New-York, where she was attacked with a quotidian fever, on the fourth of October. Ordered,

Pulv. jalap. comp. 3 is.

Sub-mur. hydrarg. grs. vi. M.

After the operation of the powder, let her take pulv. fol. eupat. perfol. grs. xx. every two hours. Oct. 6. After the cathartic had operated, she commenced with the powders, taking them as above directed: does not complain of the taste of the medicine; it sets well on her stomach. Oct. 8. Had another 
attack of fever on the sixth and seventh; bowels rather loose: let her continue in the use of the medicine, increasing the dose to xxv. grs. Oct. 10. Our patient had another attack of fever on the eighth and on the ninth; urine increased in quantity; appetite better. Oct. 13. $D \longrightarrow n$ has not had any regular attack of fever since the last report, though at times, slight febrile symptoms have affected her: let her continue in the use of the medicine. Oct. 25. It is fifteen days since our patient has had any fever; has not taken any medicine these five days past; feels her strength quite restored, and has a good appetite. Discharged, cured.

Case 4. Mary $\boldsymbol{H} \longrightarrow d$, born in Ireland, aged sixty-seven, is very much debilitated, is affected with a quotidian intermittent, which attacks her at ten o'clock in the morning, and continues until about three o'clock in the afternoon; pulse small and slow, bowels costive, tongue furred, appetite bad. These attacks of intermittent began on the tenth of 
Oct. last. After the operation of a dose of the sulphate of soda ordered the pulv. fol. eupat. perfol. 3 fs. one to be taken every two hours in wine, while free from fever.

Oct. 12. Yesterday had another attack of fever, the chill was quite severe; since the last report has taken $3 \mathrm{ij}$ (s. of the eupatorium which sits well on her stomach; says that immediately after taking a powder she feels some moisture on her skin : has some dizziness in her head, yet feels better this morning. The hour has past in which she expected the attack; pulse quicker and fuller, tongue a little furred, urine increased in quantity. Oct. 14. $\boldsymbol{H} \longrightarrow \boldsymbol{d}$ has not had any regular attack of fever since the last report; continued to take the powders regularly through the day but omitted them in the night. Oct. 26. $H-d$ has not had any fever for fourteen days; is quite recruited in strength and spirits; has not taken any medicine since the nineteenth, appetite still continues quite good. Discharged, cured. 
CASE 5. William $C-g$, born in NewYork, aged five years, is affected with a quotidian intermittent, which generally attackø him between one and two o'clock in the afternoon, and continues until evening. Was first attacked on the seventh of October, and had regular accessions of fever on the seventh, eighth, and ninth. On the tenth gave him a strong decoction of the flowers of the eupatorium. October 11. The decoction vomited him very freely, and shortened the chill and fever, by producing perspiration; was ordered the pulv. fol. eupat. perfol. gr. x. every two hours, while free from fever. Oct. 13. Our patient has not had any fever since the last report; has taken the powders regularly, and is quite fond of taking them; pulse rather quick, but full; bowels regular; skin moist; urine increased in quantity; tongue a little furred: let him continue in the use of the medicine. Oct. 16. $\mathrm{C}-\mathrm{g}$ still continues free from fever, since the last report: pulse natural; bowels regular; skin moist; tongue clean. Oct. 25. It is now fourteen days since our 
patient had any fever; has not taken any medicine for six days past. Discharged, cured.

CAsE VI. Sarah and Martha B-d, the first aged four, the last two years and six months: they are effected with tertian intermittents. The first is attacked about nine o'clock in the morning, and continues until afternoon: the last is attacked about the middle of the day, and continues until evening: pulse accelerated; bowels loose; tongue furred; skin dry; appetite in both very bad. The eldest was first attacked about three weeks since, the youngest about one week; their mother informs me, that the fever was regular as to the time of attack. Oct. 22. Ordered, the pulv. fol. eupat. perfol. grs. x. in syrup, to be given to the eldest, every two hours, while free from fever; and pulv. fol. eupat. perfol. grs. vi. for the youngest. Oct. 24. Our patients had each an attack of fever yesterday; had each taken four powders, and did not complain of the taste of the medicine: 
pulse regular; bowels still loose; tongue furred; appetite not very good. Nov. 3. The patients have continued taking their medicine until the first instant: the eldest has not had any fever since the twenty-third; the youngest has not had any since the twenty-fifth of last month : pulse natural; bowels regular ; tongue clean; appetite very good; urine somewhat increased in quantity. Both discharged, cured.

To the above cases of intermitting fever, which were distinctly marked, and which were effectually cured by the use of the eupatorium perfoliatum, given either in decoction or in substance, the writer might have added very many others. But to have done this would have far exceeded the ordinary limits of an inaugural dissertation. In simple intermittents, admitting of distinct intermission, it is asserted to have been exhibited with uncommon advantage. That such is the fact with regard to the medical properties of this species of the eupatorium was abundantly proved from the uniform result of almost every case 
of that type of disease, as it occured in the New-York Alms-house. Perhaps, too, this important fact will be the better kept in mind when I state, that from the very successful administration of this remedy, in this disease, in the year 1812, the practice of depending upon it, to the exclusion of the Peruvian bark and other ordinary remedies, for the cure of intermittents, seemed perfectly justifiable, and subsequent experience in that extensive charity has fully confirmed all that was anticipated.

\section{Remitting Fever.}

With regard to the treatment of remitting fevers and other disorders of a febrile character, I am disposed to believe that it will be found an efficacious medicine. In the management of remittents, particularly, many opportunities occured of testing its value. As a sudorific it produced the most salutary effects, and in those instances in which tonics were indicated, its administration was attended 
with equal advantage, when had recourse to for that purpose. Many cases might be here detailed in confirmation of this opinion. A more extensive employment, therefore, of this plant in febrile disorders, than Dr. Bartos is disposed to admit, will, I think, be justifiable.

\section{Yellow Fever.}

In the treatment of the yellow fever, as it has prevailed in the United States, and in other diseases of a contagious nature, whether depending upon epidemical causes, or upon the introduction of a specific matter iritroduced into the system, the eupatorium perfoliatum will be found a powerful remedy. As to the yellow fever, however diversified the opinions which have been entertained of its peculiar nature, and however various the modes of treatment that have been adopted by different physicians, as the disease has appeared in different years, in the various parts of our country, there can be little doubt, that the sudorific method of cure has, upon the 
whole, been attended with more success than either the blood-letting or mercurial practice. During the prevalence of this epidemic in the city of New-York, in the year 1795, 1797, 1798 , and in 1805, great dependence was placed upon those remedies whose operation was more immediately evinced by their action upon the surface of the body: this was particularly the case, in the treatment of this epidemic, when it prevailed with its greatest mortality in 1798. From the records which exist of that epidemic, it appears, that, by some practitioners, recourse was had chiefly to mercurial remedies; that some made liberal use of blood-letting and other active evacuants, while others again placed their chief dependence upon moderate evacuants and sudorifics. But without enlarging upon this point, I shall briefly state the opinions of Dr. Hosack and Dr. BARD, the distinguished President of the College of Physicians and Surgeons. Having had the most extensive opportunities of witnessing this disease, and of ensploying the different methods of treatment, they bear the 
most unequivocal testimony in its favour. In the yellow fever of 1798 and 1799, after the necessary evacuations of the first passages had been procured, almost exclusive dependence was placed upon sudorifics.* Of these sudorifics, the eupatorium, admininistered in the form of decoction, was deservedly considered of great value. Its primary operation was in promoting the cuticular discharges.

\section{In Typhoid Peripneumony.}

'The disease, called by some practitioners the petechial or spotted fever, and, by others, the malignant pleurisy or typhoid peripneumony, and which, within these few years past, has prevailed to such an extent in different parts of the United States, more especially in the eastern districts, and in the northern and

* See Hosack's letter to Dr. Currie, in Dr. Currie's sketch of the yellow fever, as it prevailed is Philadelphia in 1799. See also Stevens's letter on the Bone-set, in MrTChILl and MilleR's Medical Repository, hexade 2. vol. 1. p. 12. 
western parts of New-York, appears, from an examination of the various accounts that have been published, to have been more successfully treated by the class of remedies denominated sudorifics than by any other. The elaborate and able Report published by the Massachusetts Medical Society relative to the petechial fever, as it appeared in $180 \%$ and 1808 , is of itself suficiently satisfactory on this point.* But we may also add, that a similar opinion is maintained by those who lave witnessed this disease, as it has appeared with no less mortality in the state of New-York. See the respective observations of Dr. Hudson, $\dagger$ of Dr. Mañ, of Dr. Williamson, and of Dr.

* Medical Papers, communicated to the Massachusetts Medical Snciety, vol. 2. pt. 2.p. 146-9. Amer. Med. and Phil. Register, vol. 1. p. 240-3.

† Remarks on the Epidemic of New-York, in Amer. Med. and Phil. Reg. vol. 3. p. 496.

$\ddagger$ Observations on the Pueumonia of New-York, in Amer. Med. and Fhil. Reg. vol. 3. p. 497.

$£$ Remarks on the Malignaut Pleurisy of New-York, in Amer. Med. and Phil. Reg. vol. 3. p. 453. 
Hosack.* In many cases of this epidemic, which occurred in the city of New-York in the winter of 1812-13, after the proper evacuants had been employed, in some instances by the lancet, and after the bowels were relieved by mild purgative medicine, among the remedies which were had recourse to in order to procure perspiration, such as the infusion of snake root, wine whey, \&c. the eupatorium also proved highly serviceable. That a remedy like the eupatorium, possessing such active properties as a sudorific, should prove useful in a disease so generally characterized by symptoms of great debility, can easily be explained, when we revert to its chemical analysis, and consider its tonic, and consequently its cordial, properties.

* Observations on the Peripneumonia Typhodes of NewYork, in Amer. Med. and Phil. Reg. vol. 3. p. 448. 


\section{Cutaneous Distases.}

In many of the diseases arranged under the class denominated cutaneous,*. whether depending upon a peculiar habit of hody, or arising from specific morbid matter introduced into the system, we have sufficient evidence to beliere that the eupatorium may be employed with great advantage. Its general action upon the secretions, particularly those of the surface of the body and upon the urinary organs, presents sufficient proof, that in those cases in which alteratives are indicated, it will be productive of very salutary effects; and such indeed was found to be the fact in the management of a particular and distressing affection of the herpetic kind, which was formerly very common in Virginia, and there known by the name of the James' River ringworm; so called because the disease was especially prevalent among the inhabitants who

* See Dr. Willan's arrangement of Cutaneous Diseases. 
resided upon the upper streams of James' River. Upon the authority of Dr. Barton,* we are informed, that in this affection the eupatorium perfoliatum was very beneficial. “'The patient," says he, "drank a decoction of the plant, and continued the use of it for some time. It sometimes puked, it no doubt purged, and in all protably it operated as a sudorific." In treatment of the influenza, or epidemical catarth which prevailed so generally in the United States, in the year 1807, this vegetable, both in the form of a simple decoction and in that of infusion, proved lighly serviceable. In the former preparation it was useful from its mild emetic qualities, "and from its action upon the skin; in the litter its salutary operation was caused by its cordial and tonic properties. In the treatment of other diseases, depending upon epidemical causes, such as measels, scarlatina, small pox, \&c. this plant will also be found deserving of attention.

* Collections towards a Materia Medica. 


\section{Diseases of Debility.}

The powerfully tonic effects of this plant have already claimed our attention when considering its chemical analysis, and the observations which were made upon its employment in the treatment of intermittents, and the cases of this disease which were effectually cured by it, present a practical illustration of what was at first advanced. That a remedy which in one form can arrest the paroxysms of an intermittent, might in another form possess tonic properties calculated to do much good in disorders arising from general debility, needs no effort of the imagination to conceive. During the writer's attendance in the NewYork Alms-house in the year 1812, very liberal recourse was had to this remedy in diseases of this kind. The preparation for the most part employed, was an alcoholic tincture of the pulverised leaves and flowers. In general anasarcous affections of the extremities, whether occurring as symptomatic of other diseases, 
or depending upon a debilitated habit of body, this remedy in many cases was a convenient and salutary medicine. In ascites, when it may be considered as a disease of debility, that is, when it does not arise from general plethora of the system and fulness of the blood vessels,* the alcoholic tincture may be safely recommended as an excellent tonic; and it is worthy of remark, that in as much as it possesses, to a considerable degree, in addition to its tonic effects, the properties of a dinretic, it may be the more advantageously employed in cases of this kind.

* This discrimination between the different kinds of dropsy necessarily leads to the most important practical application. The eupatorium as a tonic canuot but be pernicious in diseases depending upon a general fulness of the habit. And that dropsy depends, in a majority of cases, upon this cause, is confirmed by the experience of all who have en. joyed opportunities of observation in this disease. Indeed, there is as good reason for considering dropsies in their active and passive stage, as there is for dividing inflammation into acute and chronic. MS. Notes on Ho. sack's Lectures. 
I should be wanting in those feelings of respect which I ought to cherish toward the university in which $I$ have acquired the elements of my medical education, did I not now, when about to receive its honours, present my grateful acknowledgments to the respective professors of the college, for the liberal aid imparted me by their able lectures during the progress of my medical studies. 


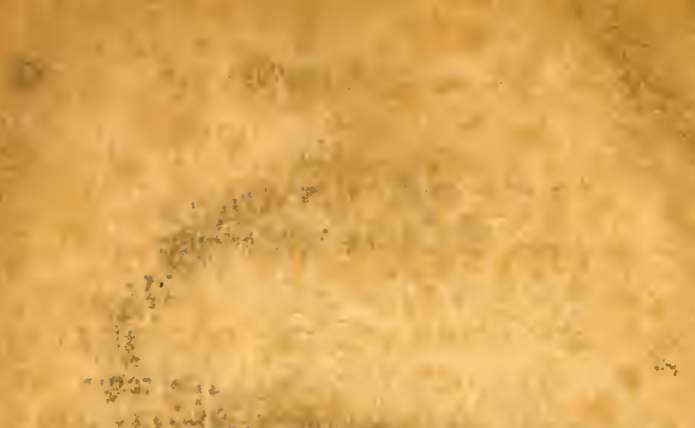
${ }_{4}^{3}$ 





